\title{
Industrial location, spatial discrete choice models and the need to account for neighbourhood effects
}

\author{
Luisa Alamá-Sabater · Andrés Artal-Tur · José Miguel Navarro-Azorín
}

\begin{abstract}
This research, following the original contributions of Vichiensan et al. (J East As Soc Trans Stud 6:3789-3802, 2005; Mixed Logit Model Framework with Structuralized Spatial Effects: a Test of Applicability with Area Unit Systems in Location Analysis; EASTS, Tokyo) and Autant-Bernard (Eur Plan Stud 14:1187-1208, 2006; Where do firms choose to locate their R\&D? A Spatial Conditional Logit analysis on French data; Routledge, London), employs a spatial conditional logit framework in order to explore the role that inter-territorial spillovers play in driving the location choices of industrial firms. After introducing neighbourhood effects into the theoretical model, we test the methodology by using data on 8,429 firms established in the municipalities making up the Spanish region of Murcia. Our results show that human capital, agglomeration economies and industrial land availability are the main factors driving entrepreneurs' decisions. Estimates of the spatial component of the model indicate that spillovers or externalities taking place between municipalities (inter-territorial spatial effects) have a remarkable influence on the location decisions of the firms, thus confirming the need to account for such spatial dependence pattern when studying location decisions of industrial companies at a local level.
\end{abstract}

Keywords: Spatial econometrics, industrial location, spatial conditional logit, inter-territorial spillovers

JEL Classification R12, R30

The article has benefited from the comments of participants in 3rd Seminar Jean Paelinck on Spatial Econometrics (Cartagena (Spain),October 2008), and in 3rd World Conference of the Spatial Econometrics Association (Barcelona (Spain), 8-10 July 200). A. Artal acknowledges financial support from the Spanish Ministry of Science and Innovation (project number ECO 2008-04059/ECON) and from Fundación Seneca-Región de Murcia (project 11897/PHCS/09ECO). Jose Miguel Navarro acknowledges financial support from Fundación Seneca-Región de Murcia (project 08736/PHCS/08). Luisa Alamá acknowledges financial support from the Spanish Ministry of Fomento (project MIFI 3239/2008).

Luisa Alamá-Sabater

University Institute for Local Development (IIDL)

Department of Economics - University Jaume I

Campus del Riu Sec, E-12071 Castelló de la Plana (Spain)

e-mail: alama@eco.uji.es

Andrés Artal-Tur (corresp. author) · José Miguel Navarro-Azorín

Department of Economics - Technical University of Cartagena

$\mathrm{C} \backslash$ Real, 3, 30201 Cartagena (Spain)

e-mails: Andres.artal@upct.es·Jmiguel.navarro@upct.es 


\section{Introduction}

When deciding to start a new business, the choice of where to locate the facilities is one of the most crucial steps of the process. The decision is so important that it could determine the success not only of the firm's current activity but also its future (Strotmann 2007). Increasing complexity is undoubtedly a feature of today's international economy with many variables affecting location decisions, making this a key issue in the firms' strategies. In this context, it is not difficult to understand why we have seen a renewal of interest in location studies in recent decades (McFadden 2001; McCann and Sepphard 2003).

Empirical studies of industrial location have been one of the most active lines of research in this field since the late 1980s, with academic contributions pursuing to identify the main factors driving firms' choices. One important field that has been driving the industrial location literature is that of understanding the role that external economies or spillover effects play in influencing companies' decisions. The analysis of agglomeration economies and the role of space represent two of the pivotal research topics in this area of study, having already attracted the attention of pioneer authors as Johann Heinrich von Thünen and Alfred Marshall, and they continue to inspire the work of influential researchers (see, i.e., Ellison et al 2007; Fujita and Thisse 2002). In order to indentify the role played by these variables, and from a methodological point of view, the literature on the determinants of industrial location has adopted two different econometric approaches: Discrete Choice Models (DCM) and Count Data Models (CDM) (Arauzo et al. 2008). While DCM are focused on the firms' decision-making problem itself and analyse the way in which the characteristics of the decisionmaker, such as firm size, sector of activity, etc., affect its choice, given the set of geographical alternatives available (Mc Fadden 1974; Carlton 1983), CDM follow an alternative path. Using the number of companies established in a particular location for a period of time as the dependent variable, they relate ex-post observed choices to the particular characteristics of the locations (Becker and Henderson 2000). 
As a corollary to this methodological debate, the important contribution of Guimarães et al. (2004) noted that both approaches essentially rely on the same theoretical framework, that is, a profit maximisation problem in which firms choose the location that reports the highest expected profit. Moreover, these authors demonstrate that, from a computational perspective, the two models are similar, because of the equivalence of the likelihood function for the conditional logit and the Poisson distributions. Their conclusion is that it is possible to recover conditional logit parameter estimates from CDM results. This contribution has stimulated a number of empirical studies on location choices in recent years, given that $\mathrm{CDM}$ appear to be tractable when the number of alternatives becomes too large, as in industrial location studies, while this is not the case for DCM. ${ }^{1}$

In this context, one remaining limitation of the theoretical approach used in location studies relates to the way in which spillover effects are modelled. In the traditional framework, the decision-maker uses only information on each individual location when computing the expected profit function of establishing in that particular geographical unit. That means the theoretical model is defined only for coping with intra-territorial spillovers and is not able to account for interterritorial ones. However, as the spatial economy literature highlights, the value achieved by a variable (i.e. a firm's profits) in one particular location may be affected by the realisation of the same, or other, variables in nearby locations. This is due to spatial dependence effects (Anselin 1988) and the presence of external economies and spillovers (Fujita and Thisse 2002). Accounting for the role of inter-territorial external economies is, then, shown to be an important variable influencing location processes, especially when the territorial unit of study is becoming ever smaller, as in local analysis. To this end, a natural extension of the theoretical model for location studies should incorporate these potential spatial effects into the decision-making process.

\footnotetext{
${ }^{1}$ Particularly, when DCM include a significant number of location alternatives for the decisionmaker, for example greater than 50, the computational needs for compiling the database as well as for running the estimation procedure usually exceed the possibilities of current techniques, even for non-standard software and hardware. In addition, there are other differences between the two families of models, but as this topic does not constitute the real focus of the paper, we refer the interested reader to the excellent discussions of Kim et al (2008), Arauzo et al (2008) and Bradlow et al 2005.
} 
Despite the importance that the topic of location choices has shown in guiding the decisions of entrepreneurs, managers and policy makers, and although this has proved to be a very fertile field of research, little work has been done to date on incorporating spatial dependence into these types of models, particularly for the discrete choice framework (Fleming, 2004). Early contributions in this literature take the simple form of spatial binary choice models (Murdoch et al. 2003; Marsh et al. 2000), with recent developments of spatial probit models (Coughlin et al. 2004) since the launch of the Spatial Econometrics toolbox for MATLAB by professor James P. Le Sage. Other recent contributions include the use of spatial multinomial logit models, with interesting applications to environmental and transport planning studies (Nelson et al. 2004; Mohammadian et al. 2003), but the literature is clearly at a very early stage concerning the use of spatial conditional logit models, the family of DCM usually employed in industrial location studies.

To the best of our knowledge, there are only two references in the literature that extend the conditional logit model to account for potential spatial effects. The first one is the paper of Vichiensan, Miyamoto and Tokunaga (2005), which extends the conditional logit model by considering a spatial autoregressive structure in both the deterministic and the stochastic part of the model specification. The idea is to capture external economies that influence the decision-maker in his/her location choice. However, the exercise is devoted to a residential choice analysis in Senday City (Japan), and its focus is more on identifying how the geographical dispersion of alternatives affects the decision-maker's choice. In their exercise, the significance of the spatial variable of the model appears to be highly dependent on the spatial pattern that characterises location alternatives. The main drawbacks of this approach stem from the computational difficulties it poses with a large set of alternatives, as estimation would turn into a very complex, maybe unfeasible, task.

The second reference is that of Autant-Bernard (2006), who implements a conditional logit model in order to search for the location determinants of R\&D laboratories in France. The unit of analysis employed is the administrative region (NUTS 2) and the model incorporates a spatially lagged term for every explanatory variable in order to determine the spatial scope of knowledge 
spillovers, both for public and private investments. The estimation results show that only private $R \& D$ expenditure appears to generate inter-regional knowledge spillovers that influence location decisions of R\&D labs in France.

To this end, the aim of this paper is to introduce inter-territorial spillovers into the theoretical model used in industrial location studies. Furthermore, and relying on the spatial conditional logit framework, we estimate the role played by external economies between neighbouring territories when influencing firms' decisions to choose their preferred location. Two contributions are made to the literature. The first is analytical and seeks to improve the empirical identification of such spatial effects or externalities. In dealing with this objective, we use local data on municipalities as our geographical unit of analysis, which is a new feature for this spatially-extended literature and constitutes the ideal empirical approach, as recent contributions have noted (Arauzo 2008; Holl 2004; Fujita and Thisse 2002). The second is methodological, and consists of extending the theoretical model for coping with inter-territorial externalities, which now enter the information set of the firm's decision-maker. Furthermore, we define an econometric specification that allows for estimating the role played by such spatial effects in industrial location processes. The proposed methodology may be used to substantiate a theoretical model of spatial dependence in industrial location studies.

In order to test this methodology, we study the factors driving location choices of 8,429 industrial establishments in the Spanish NUTS 2 region of Murcia. The availability of detailed micro-data on industrial firms and on the territorial characteristics of municipalities for this region offers an excellent opportunity to obtain empirical evidence on the performance of our methodological proposal. The industrial tradition in this regional area supports such a study. To anticipate some of the results, we find that human capital, agglomeration economies and industrial land availability are the main forces driving location decisions for industries in this region, with estimates on the spatial component of the model showing that inter-territorial externalities or spatial effects have a remarkable influence on firms' location decisions. Attributes of neighbouring municipalities are found to exert nearly the same influence as those of the selected municipality in guiding the decision-maker's choice, thus confirming the need to account for 
such spatial interdependences when studying location choices of industrial companies at a local level.

After this introduction, the remainder of the paper is organised as follows. Section 2 defines the theoretical framework of the paper. Section 3 describes the data set used in the investigation and discusses the empirical results obtained in the estimation process. Finally, section 4 summarises the main conclusions of the research.

\section{Spatial discrete choice models and location processes}

Our theoretical model builds on the standard random utility maximisation (RUM) framework employed to analyse the firms' location behaviour. In this framework, firm $i$ decide where to locate, among a finite set of $J$ alternatives (municipalities), according to the expected profit that every location $(j)$ is reporting. The choice could be described as a maximisation problem of the profit function of the firm, a function given by:

$$
\pi_{i j}=X_{j} \beta+\varepsilon_{i j}, \quad i=1, \ldots, N ; j=1, \ldots, J .
$$

where $X_{j}$ is a $1 \times M$ vector of local geographic and socio-economic conditions, $\beta$ is a vector of parameters, and $\varepsilon_{i j}$ is a random error term capturing the characteristics of the decision-maker or unobservable attributes of the choices. ${ }^{2}$ Under profit-maximising behaviour, municipality $j$ is chosen by the firm $i$ as the preferred location always that,

$$
\pi_{i j} \geq \pi_{i k}, \quad \forall k \neq j, k=1, \ldots, J,
$$

that is, the alternative $j$ is chosen when its attributes ensure the greatest expected profit to the firm. Therefore, the probability that a firm $i$ is located in the municipality $j$ yields

$$
P_{j}=\operatorname{Pr}\left(\pi_{i j} \geq \pi_{i k}, \forall k \neq j, k=1, \ldots, J\right) .
$$

\footnotetext{
2 The error term is assumed to be uncorrelated across choices, what leads to the usual assumption on the independence of irrelevant alternatives (Carlton 1983; McFadden 1974). 
It can be shown that, if disturbances are independent and identically distributed following a Weibull distribution, then the probability that the firm $i$ chooses alternative $j$ is (McFadden 1974; Greene 2008),

$$
P_{j}=\frac{\exp \left(X_{j} \beta\right)}{\sum_{k=1}^{J} \exp \left(X_{k} \beta\right)} .
$$

At this point, it is important to note that in the standard theoretical framework the firm counts on information about the characteristics of the chosen location $(j)$ together with those of the alternatives $(k)$, when deciding where to locate the business' facilities (see equations (2), (3), and (4)). Nevertheless, the decisionmaker just uses information on the characteristics of one particular municipality $(j)$ when computing the expected profit of choosing such particular location $(j)$. Then, all other (spatial) information on neighbouring locations that affects the profit of the firm is not entering the decision-maker's information set (see equation (1)). In particular, the standard specification of the theoretical model just allows accounting for externalities occurring within the spatial limits of each particular location. In this respect, the theoretical model traditionally applied in location studies faces an important limitation for dealing with the concept of interterritorial spillovers, externalities that are clearly affecting the choice of companies. $^{3}$

In contrast, recent empirical evidence and theoretical developments in the literature suggest that inter-territorial spatial effects are playing an important role in driving entrepreneurs' decisions, especially at the local level. This is because the expected profits from locating in a particular municipality would also be influenced by the characteristics of the neighbouring areas, given the existence of inter-territorial spillovers and other important linkages between firms (Ellison et al 2007; Arauzo et al 2006; Fujita and Thisse 2002; Arbia 2001). In this context, one main aim of this research is to improve the theoretical framework used in

\footnotetext{
${ }^{3}$ This is an important limitation faced by the standard theoretical framework in location studies, especially for empirical exercises employing local (municipal) data in their analysis, given that such inter-territorial spillovers or spatial effects usually play an important role in driving firms' location choices. Furthermore, if we note that the literature considers the "local dimension" as the best "spatial unit of analysis" for capturing such spillovers (Arauzo 2008; Holl 2004), this feature of the standard framework turns out to be an important limitation of the location literature itself.
} 
location studies by introducing the possibility of dealing with this type of externalities or spatial effects in empirical studies. In order to do so, we extend the specification of the standard profit function by introducing a new set of variables, which we label "neighbouring area attributes". Those attributes include the characteristics of the surrounding areas that could influence the firm's profit function and consequently its location choice. ${ }^{4}$ This new set of variables allows us to extend the information available for the decision-maker when computing the profit function, by including a term that captures the presence of inter-territorial spillovers, thereby extending the systematic part of equation (1) as follows: ${ }^{5}$

$$
\pi_{i j}=X_{j} \beta+\delta \sum_{l=1}^{J} w_{j l} X_{l} \beta+\varepsilon_{i j}, \quad i=1, \ldots, N ; j=1, \ldots, J,
$$

where $\left\{w_{j l}\right\}_{l=1, \ldots, J}$ is a weighting sequence defined in terms of the distance between municipalities $j$ and $l$. In general, we still do not address any precise definition of distance, which in general could be based on economic, geographic, or sociocultural considerations. ${ }^{6}$

In this way, the extended profit function in equation (5) now includes information about the particular municipality $j$ (collected by variables in $X_{j}$ ), together with information on the spatially weighted average of the attributes of surrounding locations (captured by the term $\sum_{l=1}^{J} w_{j l} X_{l}$ ). At the same time, when estimating equation (5) we assume for convenience that the parameters $\beta$ are the same across the whole equation. That is, we assume that each explanatory variable (or local territorial characteristic) of the model, belonging to the own chosen location $j$ or to the $J-1$ surrounding municipalities, exerts the same relative effect on the

\footnotetext{
${ }^{4}$ It is important to note that although dozens of social and economic characteristics of nearby locations could influence the firm's behaviour, we are interested in including in our extended model only those that have a direct impact on the firm's expected profits, because only those matter when building the firm's choice probability function (Train 2003).

${ }^{5}$ Note that this specification resembles the spatial cross-regressive model (Anselin 2003; Florax and Folmer 1992).

${ }^{6}$ Note that this initial approach offers the theoretical model an opportunity of becoming a valid framework for different types of location studies, as, i.e., those devoted to industrial location, marketing or even industrial organisation studies.
} 
firm $i^{\prime} s$ expected profit function. ${ }^{7}$ This working assumption allows us to specify a parameter $\delta$ in equation (5), common to all explanatory variables, that would now be capturing the average influence of the whole spatial dimension on firms' location choices. Specifically, this parameter captures, from a theoretical point of view, the relative strength that spatial inter-territorial spillovers have when affecting the choice of firm $i$, by influencing its expected profit function. In specifying this new spatial parameter, we are able to econometrically estimate the theoretical concept of inter-territorial spatial effects affecting companies' location choices, thus achieving one of the main goals of the paper.

Our approach departs from previous contributions in the literature, improving them in two ways: first theoretically, allowing for the inclusion of "neighbourhood (spatial) effects" in the expected profit function (McFadden 2001; McFadden 1978; Carlton 1983), and second empirically, providing a single measure of the influence that inter-territorial spillovers exert on the firm's choice. It is worth noting that a similar parameter which allows for globally retrieving the spatial dimension in location models is not present in this still incipient and scarce literature (Vichiensan et al. 2005; Autant-Bernard 2006). Estimates showing a positive value of the spatial parameter, $\delta>0$, would be implying that external economies among municipalities play a significant role in the firm's choice, while a negative value of the parameter, $\delta<0$, would be reflecting the existence of congestion/dispersion externalities which affect the firm's choice (Viladecans 2004). ${ }^{8}$

\footnotetext{
${ }^{7}$ This appears to be a reasonable working assumption, because location or explanatory factors usually share a similar capacity of attraction of new firms inside a limited territorial space (local neighbourhood). This is the case, for example, for municipalities belonging to a metropolitan area, where labour market conditions, accessibility to markets, infrastructures or other factors of attraction of start-up's companies use to show a similar level of development in the eyes of the decision-makers. Also, and more importantly for our investigation, the introduction of this assumption allows us to clearly specify and estimate our spatial parameter of interest " $\delta$ ", which constitutes one of the main goals of this paper.

${ }^{8}$ It is important to understand that our spatial parameter $\delta$ is defined to capture spatial effects affecting the decision-maker by using a single spatial measure, in contrast with previous contributions in the literature which estimate a spatial parameter for every characteristic of the surrounding area affecting the firm's choice (see, i.e., Autant-Bernard, 2006). In this sense, it seems that this specification of the spatial parameter remains closer to the theoretical notion of spatial dependence, which constitutes the basis of the spatial econometrics literature.
} 
Furthermore, if we assume that the error terms in equation (5) are independent and identically distributed following a Weibull distribution, now the probability of firm $i$ to choose municipality $j$ is now:

$$
P_{j}=\frac{\exp \left(X_{j} \beta+\delta \sum_{l=1}^{J} w_{j l} X_{l} \beta\right)}{\sum_{k=1}^{J} \exp \left(X_{k} \beta+\delta \sum_{l=1}^{J} w_{k l} X_{l} \beta\right)},
$$

from which it is straightforward to compute marginal effects as:

$$
\frac{\partial P_{j}}{\partial X_{l}}=\left\{\begin{array}{cc}
P_{j}\left(1-P_{j}\right) \beta & \text { if } l=j \\
P_{j}\left[\delta w_{j l}\left(1-P_{j}\right)-P_{l}\right] \beta & \text { if } l \neq j
\end{array}\right.
$$

We can also define marginal effects with respect to the spatially weighted attributes, denoted by $X_{j}^{W}=\sum_{l=1}^{J} w_{j l} X_{l},{ }^{9}$ as:

$$
\frac{\partial P_{j}}{\partial X_{j}^{W}}=\delta P_{j}\left(1-P_{j}\right) \beta
$$

By comparing expressions (7) and (8) for $l=j$ we can conclude that, for the $m$-th attribute,

$$
\delta=\frac{\partial P_{j} / \partial X_{j, m}^{W}}{\partial P_{j} / \partial X_{j, m}}, m=1, \ldots, M
$$

which means that from a theoretical point of view, and by construction, the parameter $\delta$ is measuring the relative importance that neighbourhood attributes have as compared to specific local attributes (of the chosen $j$-th alternative) in the decision-making problem. A value of $\delta$ greater than one would now be implying that the neighbourhood attributes affecting the decision of a firm located in the municipality $j$ appear to be of greater importance than those of municipality $j$ itself; that is, the firm locating in municipality $j$ is intending to benefit more from neighbourhood advantages than from its own local advantages. In contrast, a positive value of $\delta$ but below unity implies that, even though spatial effects are important for the firm, they appear to be less important as location attractors than

\footnotetext{
${ }^{9}$ Note that under this notation we can rewrite the expected profit of a firm $i$ of establishing in municipality $j$ as $\pi_{i j}=X_{j} \beta+\delta W X_{j} \beta+\varepsilon_{i j}, i=1, \ldots, N ; j=1, \ldots, J$.
} 
the specific attributes of the chosen location, what seems a more plausible expected result from a theoretical point of view. ${ }^{10}$

\section{Empirical results}

\subsection{Data}

Once defined our theoretical model, we are now interested in identifying the factors that influence the firms' location choices, as well as in capturing the role that external (inter-territorial) economies are playing in this process. In our preferred econometric specification, the dependent variable will be the number of industrial establishments operating at the municipality level in the Spanish region of Murcia in 2006. This information is obtained from the Business Directory (DAERM) of the Regional Statistical Office of Murcia, which reports data on 8,429 industrial establishments classified by municipality of location and sector of activity.

The use of municipalities as the geographical unit of analysis is important for several reasons: First, it is a novelty in the spatial conditional logit literature, given that the only contribution relying on this framework for industrial location studies, that of Autant-Bernard 2006, focus in a regional -NUTS 2- approach for France. Employing the local focus in these studies also represents the ideal approach if one wants to capture the influence of spatial spillovers or externalities in location choices. Recent contributions of the literature have shown that spatial effects appear to be really important for entrepreneurs' choices at the local level, rather than at inter-regional or inter-national ones, because externalities rapidly decline with space (Arauzo 2008; Holl 2004; Fujita and Thisse 2002). Another advantage of applying the local focus is that it allows us to overcome a common error in spatial analysis, the so-called "error measurement problem", which appears when the spatial dimension of the variable we want to measure does not properly match that of the chosen spatial unit of analysis in the research (Haining

\footnotetext{
${ }^{10}$ One must also be aware that this new spatial measure in our proposal opens interesting research possibilities to studies analysing the effects of congestion (negative spatial externalities) on location choices, a research line which is still underrepresented but increasingly necessary in this literature (see, i.e., Arauzo 2008, footnote 14).
} 
1995; Rosenthal and Strange 2003). Moreover, the use of an appropriate territorial unit of analysis which correctly resembles the decision-maker's problem deserves more precise estimation results, both in the parameters of the model and in its spatial component. This is because it reduces the omitted variables problem and improves identification and estimation of spatial effects influencing firms' choices (Arauzo 2008; Arauzo and Manjón 2004).

The dataset also comprises information on the geographical and socio-economic characteristics of the 45 municipalities making up the Spanish region of Murcia. This is obtained from the Regional Statistical Office of Murcia, which allows us to conform the explanatory variables set of the model. Detailed information on social and economic characteristics of small territorial units is not usually available with such a degree of detail. In this respect, the existence of a richer dataset for the region of Murcia has guided our decision of applying this theoretical framework to the analysis of industrial location choices in this region.

We begin by introducing agglomeration variables in the explanatory set, given their central role in the literature on industrial location. In general, agglomeration effects can be defined as external effects including all economies that are an increasing function of the number of nearby firms (Head and Swenson 1995). If the firms belong to the same industry, we define these economies as localisation economies, and in the case that they belong to different industries we label them as diversity economies. ${ }^{11}$

The concept of localisation economies is intended to capture all firm's advantages generated by the concentration of industries from the same sector close one another, due to the existence of information spillovers derived from informal contacts between the staff of the firms or whatever other externalities arising because of the firms' proximity (Arauzo et al. 2008; Figueiredo et al. 2002; Head

\footnotetext{
${ }^{11}$ A general characterisation of agglomeration economies is due to Hoover (1936), whom defined localisation economies as those arising because of the concentration of firms from the same sector of activity, while terming as urbanisation economies to those deriving from a concentration of economic activity, whatever their source. In order to differentiate from localisation economies, we have preferred to use the concept of diversity economies developed by Jacobs, given the importance shown by this type of externality in today's post-industrial economies (see, e.g., Jacobs 1969).
} 
and Swenson 1995). These type of agglomeration economies are generally identified in the recent literature as Marshall-Arrow-Romer (MAR) externalities (Glaeser et al. 1992). To measure localisation economies we use a standard index capturing the degree of industrial specialisation of municipality $j$, in terms of employment, in comparison with the specialisation that characterises the whole regional area (INDUSTRIAL SPECIALISATION). ${ }^{12}$

On the contrary, the existence of a considerable number of different industrial activities in the same location generates diversity economies, also named Jacobs' external economies (Jacobs 1969; Duranton and Puga 2000). The concept captures those external economies improving the firm's performance that stem from the diversity of industries (or services) surrounding the firm. Externalities arise because of enhanced local competition or due to the added-value it provides to the activities of the firm by improving access to new industrial inputs or services. In this paper, industrial diversity economies are captured by an index (DIVERSIFICATION) computed as one minus the Herfindalh-Hirschman concentration index. Higher values of this index are associated with a more diversified local industrial environment.

Secondly, and together with the agglomeration forces, we also include some supply-side factors in our explanatory variables set, following the literature on industrial location (Arauzo et al 2008; Ellison et al 2007). This covariate is approached through a human capital variable (HUMAN CAPITAL), computed as the percentage of the labour force that has completed secondary and tertiary level education in every municipality, what constitutes an standard approach of this type of variable in the literature (Arauzo et al 2008; Coughlin et al. 2000; Coughlin et al. 1991;). The importance of human capital, proxied by levels of education among the local workforce, for firms' location choices is well documented in the empirical literature. Some contributions even note the important role played by this variable in attracting industries with high knowledge content (Audrestch and Lemman 2005).

\footnotetext{
${ }^{12}$ See the Appendix for a more detailed description of the explanatory variables and statistical sources employed in the econometric study.
} 
Thirdly, other municipal characteristics are included as explanatory variables, such as the total municipal population (POPULATION) which acts as a demandside variable, plus other labour market (supply-side) conditions, proxied by the ratio of local industrial employment to regional industrial employment (INDUSTRY SHARE) and the corresponding measure for the service sector (SERVICES SHARE). An institutional factor is also used in our final equation (10), capturing the availability of industrial land in every municipality (INDUSTRIAL SURFACE). This serves as an endowment variable, reflecting the commitment of local and regional authorities in providing the necessary conditions for attracting new industrial establishments (Woodward 1992; Guimarães et al. 1998). In general, the pool of location factors we specify in our preferred equation is basically made up of typical neoclassical covariates within a profit-maximising framework, also including an institutionally-driven measure corresponding to the endowment variable (Arauzo et al. 2006). ${ }^{13}$

All expected coefficients for the explanatory variables of the model are assumed to be positive, as all of them strengthen the relative position of a municipality as a potential location for firms, as pointed out by the literature (Arauzo et al. 2008; Viladecans 2004).

Our final specification for the expected profit of firm $i$ when establishing in municipality $j$ is then given by,

$$
\begin{aligned}
\pi_{i j} & =\beta_{1} \text { INDUSTRIAL SPECIALISATION }_{j}+\beta_{2} \text { DIVERSIFICATION }_{j} \\
& +\beta_{3} \text { HUMAN CAPITAL }_{j}+\beta_{4} \text { POPULATION }_{j}+\beta_{5} \text { INDUSTRY SHARE }_{j} \\
& +\beta_{6} \text { SERVICES SHARE }_{j}+\beta_{7} \text { INDUSTRIAL SURFACE }_{j} \\
& +\delta\left(\beta_{1} \text { INDUSTRIAL SPECIALISATION }_{j}^{W}+\beta_{2} \text { DIVERSIFICATION }_{j}^{W}\right. \\
& +\beta_{3} \text { HUMAN CAPITAL }_{j}^{W}+\beta_{4} \text { POPULATION }_{j}^{W}+\beta_{5} \text { INDUSTRY SHARE }_{j}^{W} \\
& \left.+\beta_{6} \text { SERVICES SHARE }_{j}^{W}+\beta_{7} \text { INDUSTRIAL SURFACE }_{j}^{W}\right)+\varepsilon_{i j}
\end{aligned}
$$

\footnotetext{
${ }^{13}$ We have tested for the role of additional explanatory variables in our original specification, such as a distance variable (to the capital of the region, to some transport infrastructures as port, airport, etc.), demand-side variables (income per capita, population density), as well as other supply-side variables (several definitions of human capital by levels of education, workforce qualification, wage levels, etc.). However, many of them have not worked satisfactorily, so we have finally chosen the explanatory variables presented in this section as our preferred set.
} 
where the spatially weighted averaged variables (denoted by the " $W$ " superscript) are computed using a weight matrix $W$, what constitutes a standard of the spatial econometrics approach (Anselin 1988).

The weighting scheme of our neighbourhood attributes will obviously depend on the definition of distance used. Here we adopt a standard spatial econometrics approach by defining the weights in terms of the inverse Euclidean distance between municipalities. The exact definition then yields:

$$
w_{j l}=\left\{\begin{array}{cl}
0 & \text { if } j=l \\
\frac{d_{j l}^{-1} \mathbf{1}_{\left(d_{j l} \leq R\right)}}{\sum_{l=1}^{J} d_{j l}^{-1} \mathbf{1}_{\left(d_{j l} \leq R\right)}} & \text { if } j \neq l
\end{array}\right.
$$

where $d_{j l}$ is the Euclidean distance between municipalities $j$ and $l ; \mathbf{1}_{()}$is an index function that equals 1 when the municipality $l$ is within a circle with radius $R$ and centre in the municipality $j$, and zero otherwise. It is equally important to note that this definition of distance implies that in the decision of locating in municipality $j$, the firm is just taking into account the characteristics of the nearby municipalities which lie inside the defined circle, which we term as neighbours. This approach allows us to calibrate the extent to which spillovers exert an effect on the firm's profits function, adding some rationale in line with the most recent industrial location literature on spatial spillovers (Arauzo 2005).

\subsection{Some econometric issues about the estimation procedure}

The parameters $\beta$ and $\delta$ in equation (10) can be estimated by maximising the log-likelihood function,

$$
\log L_{c l}=\sum_{i=1}^{N} \sum_{j=1}^{J} y_{i j} \log P_{j}=\sum_{j=1}^{J} n_{j} \log P_{j},
$$

where $y_{i j}$ is an indicator function which selects out the appropriate response probability for each observation $i$, and $n_{j}$ is the number of firms which have chosen municipality $j$. 
As we have mentioned, from a computational point of view, estimating the resulting spatial conditional logit by maximum likelihood methods may be cumbersome, especially when the number of alternatives or locations becomes too large. ${ }^{14}$ Although this feature of the DCM is not shared by our present empirical exercise, we apply the estimation procedure proposed by Guimarães et al. (2003) to our spatially extended model. These authors demonstrate the existence of an equivalence relationship between the conditional logit and Poisson likelihood functions. It then would follow that estimates of the parameters in the spatial conditional logit model (5) can be obtained by using a Poisson regression. We have decided to follow this methodology because the main contribution of the present paper is methodological. Consequently, our proposal could easily be generalised to other empirical studies, which certainly have to deal with this common DCM problem. After applying the Guimarães et al. (2003) procedure, in the next subsection we discuss the estimation results of our econometric model.

\subsection{Results}

A first look at the distribution of industrial establishments in the region of Murcia shows the existence of an important degree of firm clustering, with four municipalities, Murcia, Cartagena, Lorca and Yecla, accounting for more than half $(56 \%)$ of the total number of establishments (DAERM database). This clustering pattern is also reflected by the percentile map in Figure 1, which includes information on the distribution of industrial establishments over regional municipalities. In this figure, one municipality, the city of Murcia, stays in the upper percentile, appearing to be the more attractive location for establishing an industrial company in the regional space. Other four municipalities - Cartagena, Lorca, Yecla and Molina de Segura - stay in the percentile range immediately below it, showing a similar capacity for attracting new establishments. ${ }^{15}$ The rest of municipalities do not show such central position in the regional arena, although we must distinguish between the intermediate group, made up of 19 municipalities, and the three other percentile groups ranging in the last positions

\footnotetext{
${ }^{14}$ See the introductory part of the paper, together with the footnote 1.

${ }^{15}$ The city of Murcia is the red-coloured municipality in Figure 1, with Molina de Segura located just above this municipality, Cartagena just below, Lorca on the left and Yecla right at the top of the map.
} 
of the regional industry distribution. The last group is composed by 21 municipalities - nearly half of the total 45 making up the whole region - but just accounts for $10 \%$ of total regional establishments (DAERM database). Table 1 also shows the important degree of sectoral specialisation that characterises the regional industry, with just three industries accounting for $50.5 \%$ of total establishments: Food industries, steel and metal products, and furniture and other manufactured goods. The geographical distribution of industries shows that these are mainly located in the city of Murcia and Cartagena, with furniture industry traditionally established in Yecla and food industry showing an important presence in Cartagena and Lorca.

Parameter estimates of the conditional logit model are shown in Table $2 .{ }^{16}$ First and second columns summarise estimation results obtained from applying the standard conditional logit specification; that is, without including cross spatial dependences between firms. Third and fourth columns include estimates of the spatially extended model. In this specification, we incorporate a spatially weighted average of the neighbour's attributes as an additional explanatory variable, as pointed out in the theoretical section. Table 2 also reports a collection of statistical measures of the goodness-of-fit for the model, together with a test for the value of our spatial parameter of interest $\delta$.

At this point, we must define the value of the radius $R$ we are going to use for computing the spatial weight sequence of the spatially extended covariates in the model. Given that we do not have any a priori information on the true value of the parameter, we consider a statistical criterion by choosing the value of the parameter that maximises the likelihood function for the proposed specification of the model. After implementing a grid search procedure over an interval that varies between $25 \mathrm{~km}$ and $125 \mathrm{~km}$, as the shorter and the longer distances between two municipalities in the region, our preferred specification is that with a corresponding value for radius $R$ of $43.6 \mathrm{~km}$ (see Figure 2). ${ }^{17}$

\footnotetext{
${ }^{16}$ Estimation was carried out by using the $\mathrm{GAUSS}^{\mathrm{TM}}$ CML module.

${ }^{17}$ In order to provide a proper argument for the chosen value for radius $R$, we must note that the average distance between the municipalities in the Region of Murcia is of $45.3 \mathrm{~km}$, a value certainly close to our choice. Alternatively, two studies on the Spanish economy estimate an average radius of $15-30 \mathrm{~km}$. for the local markets of the municipalities of Catalan and Valencian
} 
Turning now to the estimation results (Table 2, columns 1 and 2), it is interesting to note that all our covariates present the expected signs of the estimated parameters, except for the case of the variable SERVICES SHARE, confirming that the chosen specification of the empirical model renders consistent results in comparison with previous findings of the literature (Arauzo et al. 2006). The estimated coefficients also appear to be highly significant. Goodness-of-fit measures for our standard, non-spatial, model are equally comparable to empirical contributions in the literature, with an important level of significance for the joint model. In general, our results seem to capture the relevance that traditional neoclassical factors have in influencing firms' choices at the local level.

Both types of agglomeration economies included in our preferred specification namely localisation and diversity effects - appear as key variables in driving firms' choices. We also observe that traditional, locally bounded, spillovers have an important attraction capacity over new industrial establishments. Urban centres generate important agglomeration forces, with diversity economies appearing as the most salient agglomeration factor in the region. Entrepreneurs identify the existence of a diverse industrial environment as a positive attribute for location, the same occurring in the services sector, as previous literature has been pointing out (Fujita and Thisse 2002; Ellison et al 2007). Equally, the two more populated centres in the regional space, the cities of Murcia and Cartagena, appear to be the main destinations of industrial firms, particularly, because it is precisely there where new businesses can benefit from larger diversity economies (DAERM).

Results for the INDUSTRIAL SPECIALISATION variable show that intramunicipal externalities also play an interesting role, as they appear to be significant for the decision-maker when choosing the location of a new firm. Firms clustering together can benefit from existing externalities, arising i.e. from informal contacts between workers in the same industry, which renders important intangible assets to the companies. In this respect, the region of Murcia is

regions (Viladecans 2001, 2004). In this respect, and given that the municipalities of the region of Murcia are slightly larger on average in the national space, our estimated value for radius $R$ appears to be a plausible one. 
characterised by the existence of historically consolidated industrial clusters, as it is the case of Yecla with the furniture industry, and Lorca and Cartagena for the agri-food industry. In addition, the specialisation on industrial activities of a municipality appears as another relevant factor of attraction for new industrial firms in the region, as the estimated coefficient for the variable INDUSTRY SHARE shows. It then follows that companies in this region appreciate locations with a considerable presence of industrial firms and industrial employment, together with an important number of agglomeration economies, both diversity and localisation ones. In addition, the variable SERVICES SHARE shows no significance in its coefficient, although it presents the expected positive value in its sign.

Qualification of the labour force through educational training emerges as the most important factor influencing the location of firms in the region of Murcia, a result that points to the importance of this factor for the local (municipal) approach. It also seems to indicate that new firms confer a high value on education as a tool for developing and consolidating their activities in an increasingly competitive global economy. The remaining results for our non-spatial model indicate that firms prefer more populated municipalities to less populated ones, with the POPULATION variable acting as a demand-side location factor, although the variable shows a small elasticity value. Similarly, the institutional variable of the model (INDUSTRIAL SURFACE), which captures the availability of industrial land in municipalities where the firm's plant is built, is found to be another important factor influencing location decisions. Quantitatively, it is the third most important factor in guiding such choices, just below human capital and the degree of specialisation in industrial activities of the municipality where the firm establishes itself. This result again reflects the important role that public authorities could play in managing local and regional development policies, by providing a suitable environment where industrial firms can start up and consolidate their activities, as other authors have shown (Woodward 1992; Gabe and Bell 2004).

Extending the conditional logit model by introducing the spatially extended set of covariates allows us to test for the influence of inter-territorial (neighbourhood) 
spillovers in firms' location choices. Results from estimating the spatial conditional logit model are collected in Table 2 (columns 3 and 4). In general, we observe that our results for the extended model closely follow those of the nonspatial one. The only exception being the SERVICES SHARE variable which now shows a negative sign in its coefficient, although it continues to be insignificant. The rest of coefficients appear to be highly significant, showing a reduction in their absolute values in comparison with those of the non-spatial model, except for INDUSTRIAL SURFACE and DIVERSIFICATION variables which show a slight increase in their estimated values. As our first general conclusion, we must state that the spatially extended conditional logit model employed in the research seems to perform very well, helping the researcher to highlight the important role played by local factors and inter-municipal spillovers in the choice of firms (Arauzo et al. 2008).

Regarding our spatial coefficient of interest $\delta$, we obtain an estimated value of 0.83, which also appears highly significant. Moreover, we have tested whether this spatial coefficient is above or below unity value, and we have been unable to reject the hypothesis that it is equal to or below one $(\delta \leq 1)$, what reinforces our theoretically-informed perception on what this value should be (Table 2). ${ }^{18}$ According to the theoretical framework summarised in equation (5), this value implies that the characteristics of the chosen municipality appear to be more relevant than those of the neighbourhood for the decision-maker's choice, what seems to be a plausible result. In comparison with the results of Autant-Bernard (2006), and although we do not share the same methodological approach, a pseudo- $\delta$ can be inferred from her paper for the only particular spatially lagged location factor that appears to be statistically significant. It would render an inferred parameter of around $0.25-0.33$ for the NUTS 2 regions of France. ${ }^{19}$ Combining her and our results, we would infer that spillovers appear to be more important (three times as important) at a local (municipal) level than at a regional one. In Autant-Bernard's own words, that would add new evidence "supporting

\footnotetext{
${ }^{18}$ Tests for checking robustness of the results are carried out along the empirical study, with all of our slightly modified specifications showing similar results.

${ }^{19}$ This exercise implies introducing our working assumptions in her framework of analysis, that is, assuming equality of her estimated $\beta$ 's between the own region's covariates and that of the spatially extended variables, and then extracting the inferred $\delta$ from her outcomes.
} 
the hypothesis of a decline of knowledge diffusion over space" (ibid, p. 1196). This is a pivotal result of the investigation because it confirms the usefulness of the parameter $\delta$ in location studies, and the need to account for inter-territorial effects in the industrial location analysis.

Further results are obtained by computing elasticities for the estimated model for every municipality in our sample, making up the whole region of Murcia. ${ }^{20}$ Note that we have calculated elasticities for both the standard conditional logit (Table 3) and the spatially extended model (Table 4). A detailed analysis of the elasticities by municipalities provides us with richer information, useful in guiding local policy in this regional environment. Our results suggest that the most important factor at municipal level is the existence of an important stock of human capital, here proxied by the fraction of the labour force which has completed secondary-level and further or higher education. In fact, the estimated elasticity for this variable (HUMAN CAPITAL) is above a value of 2 for all the municipalities, according to the results of the spatial conditional logit model. The second variable in terms of importance for the firm's choice is the ability to benefit from agglomeration economies, with diversity economies playing a more important role than specialisation ones.

It is worth noting that the provision of urban land for new industries by the public sector (INDUSTRIAL SURFACE) is also a very important location factor, particularly for firms establishing in certain municipalities of the region, such as Lorca, Jumilla or Moratalla, which are rather distant from the administrative centre of the region (city of Murcia). On the contrary, the presence of a considerable number of industrial jobs in the chosen municipality, what reflects some local specialisation in industrial activities, as well as the level of demand for products, approached by the population factor, turn out to be the least important factors driving firms' choices. Notwithstanding, the level of demand appears to be an important location factor for companies established in the most populated

\footnotetext{
${ }^{20}$ Elasticity values are computed employing (evaluating) the observed value of every explanatory variable in the correspondent municipality. Elasticities are common in economics, providing unitfree measures of the degree of responsiveness of the dependent variable to changes in covariates. In our case, computed elasticities gives the percentage change in the probability of a firm locating in a given municipality as a result of a $1 \%$ increase in one of the municipality's attributes.
} 
municipalities of the region: Lorca, Cartagena and the city of Murcia, showing a value for their respective elasticities for this factor of $0.3,0.7$, and 1.0. In general, if we compare the results for the spatial and non-spatial specifications of the model in Table 2, we observe that the introduction of inter-territorial spatial effects result in an increase in the value of estimated elasticities for DIVERSIFICATION and INDUSTRIAL SURFACE variables. Also, we observe a reduction of the value of elasticities for the rest of covariates, especially for the INDUSTRY SHARE variable, which coefficient shows a remarkable decrease.

Finally, we have computed the corresponding value of the probability of locating in every individual municipality of the region that the decision-maker assigns, using the estimated coefficients of the model. We include these results in the last column of Tables 3 and 4. Obtained probabilities, as a summary result, allows us to conclude that the main urban locations of the region appear to maintain a higher capacity of attracting new industrial firms, with probabilities ranging from 30 per cent for the city of Murcia, and 8 and 6 per cent for Yecla and Cartagena. In general, these municipalities also show higher elasticity values for each individual location factor included in the model, as one would expect in the case of the main urban centres in the regional space.

\section{Conclusions}

Industrial location literature has undergone a boom in the last two decades, with a primary focus on identifying the main factors driving firms' location choices in an increasingly globalised world economy. The refinement of empirical methods used in such studies has helped scholars to better understand the circumstances characterising these processes. The role played by externalities or spatial effects in influencing companies' choices continues to be one of the most vibrant topics in the literature.

In this context, this research has been directed at continuing with the analysis of this central variable in two ways. Firstly, we have employed the local approach in our study, using municipality data as the spatial unit of analysis. This is a novelty in such studies and has proved to be an appropriate empirical focus in dealing with spillovers, as noted in the New Economic Geography literature. We have 
shown that such spatial effects play a key role in influencing firms' decisionmakers, thereby confirming the findings of previous investigations. Secondly, we have extended the theoretical framework used in industrial location studies in order to cope with inter-territorial spillovers, a spatial dimension of externalities not allowed for by preceding contributions. We have also shown the importance of such contribution in this type of studies, especially for those applying the local approach. Confirmation of the existence of intense spillover effects and the importance of inter-territorial externalities for firms' location choices at local level are two primary contributions of the research, constituting a new feature in the spatial approach of industrial location studies.

After introducing our theoretical framework, we have empirically tested this methodology by using a conditional logit model with spatially lagged explanatory variables. In the specification for the econometric model, we have introduced a spatial coefficient as another new feature of this literature. This parameter has served to quantify the strength that neighbourhood effects (inter-municipal spillovers) exert on the firms' choice, thus allowing for a better understanding of the role played by such spatial effects at a local level. Definition of distance in our spatially extended conditional logit model adds another unique feature to the paper, contributing to the debate on how to build the weight matrix and handling with distances and space in extended models, an important and still open debate in the spatial econometrics literature.

The estimation results for our model, using detailed data on 8,429 firms located in the municipalities of the Spanish region of Murcia, appear to be largely consistent with those of previous studies on industrial location. Estimates of the spatial conditional logit have shown the important role played by local and neighbourhood attributes in order to increase the attractiveness of a particular location for new industrial establishments. The presence of a highly educated and qualified workforce appears to be the most important factor in driving firm's decision-makers choices, followed in importance by the availability of industrial land at the municipality level, and the presence of important agglomeration economies, both of diversity and localisation. An important domestic local market for services, that is, an important specialisation of the municipality in those type of activities, do not show the relevance encountered in other studies for our 
regional case. However, the size of the local market appears to be relevant for industries located in the main urban centres of the region of Murcia.

In general, our findings have shown that accounting for inter-territorial spillovers is pivotal for this type of studies. Attributes of neighbouring municipalities appear to be nearly of the same importance as those of the chosen municipality itself, for the decision-maker. Similarly, our results seems to reflect that spatial spillovers are of greater extent at a local level than at a regional one, what reinforces the empirical evidence of a decline of spatial externalities over space. This result again points to the need of accommodating the spatial unit of analysis to the theoretical concept one wants to capture empirically in the study of such spatial effects, this being an important recommendation for regional studies. In this sense, the use of the municipality as the geographical unit of analysis has proved appropriate in order to capture spatial spillovers in the conditional logit approach.

Finally, our results have important implications in terms of regional policy. Firstly, they highlight the need to continue improving supply-side factors in order to push industrial development at a regional scale. Improving the educational training of the labour force appears as the most salient policy a locality could pursue for attracting new business in its geography. Secondly, agglomeration economies and other spatial spillovers not locally-bounded continue to be first order factors influencing industrial location processes. Consequently, policies directed to promote spatial clustering of firms continue to be important as an instrument to consolidate industrial areas at a local level. Promoting a rich and diverse industrial environment is even more important for pursuing this objective, as our results have shown. Institutional factors also appear to be important, so industrial policy at a regional and local level should be more proactive if it wants to affect location choices, especially in a time of crisis. And thirdly, demand-side factors, such as the magnitude of potential demand, are also shown to be important once a certain threshold level has been exceeded. In summary, the results of the research have shown that this new framework of analysis appears to be useful if the researcher wants to gain a deeper understanding of the firms' location decisions, which, in turn, may obviously help in the design of more efficient regional policy measures. 


\section{References}

Anselin L (1988) Spatial econometrics: methods and models. Kluwer Academic Publishers, Dordrecht

Anselin L (2003) Spatial externalities, spatial multipliers, and spatial econometrics. Int Reg Sci Rev 26:153-166

Arauzo J M (2005) A note on spatial autocorrelation at a local level. Universitat Rovira-i-Virgili WP $03 / 2005$

Arauzo J M (2008) Industrial location at a local level: Comments on the territorial level of analysis. Tijdschr Econ Soc Geogr- J Econ Soc Geogr 99:193-208

Arauzo J M, Manjón M (2004) Firm size and geographical aggregation: and empirical appraisal in industrial location. Small Bus Econ 22:299-312

Arauzo J M, Liviano D, Manjón M (2008) Empirical studies in industrial location: An assessment of their methods and results. Universitat Rovira-i-Virgili WP 06/2008

Arbia G (2001) The role of spatial effects in the empirical analysis of regional concentration. J Geograph Systems 3:271-281.

Audretsch D, Lehmann E (2005) Does the knowledge spillover theory of entrepreneurship hold for regions?. Res Pol 34:1191-1202

Autant-Bernard C (2006) Where do firms to locate their R\&D? A spatial conditional analysis on french data. Europ Plan Stud 14:1187-1208

Becker R, Henderson V (2000) Effects of air quality regulations on pollution industries. J Polit Economy 108:379-421

Bradlow E T, Bronnenberg B, Russell G J, Arora N, Bell D R, Duvvuri S D, Hofstede F, Sismeiro C, Thomadsen R, Yang S (2005): "Spatial Models in Marketing", Marketing Lett 16: 267-278.

Carlton D (1983) The location and employment choices of new firms: An econometric model with discrete and continuous endogenous variables. Rev Econ Statist 65:440-449

Coughlin C C, Terza J V, Arromdee V (1991) State characteristics and the location of foreign direct investment within the United States. Rev Econ Statist 73:675-683

Coughlin C C, Segev E (2000) Location determinants of new foreign-owned manufacturing plants. J Reg Sci 40:323-351

Coughlin C, Garret T, Hernández-Murillo R (2004) Spatial probit and the geographic pattern of state lotteries. Working Paper Series 2003-042, The Federal Reserve Bank of St. Louis

Duranton G, Puga D (2000) Diversity and specialisation in cities: why, where and when does it matter?. Urban Stud 37:533-555 
Ellison G, Glaeser E L, Kerr W (2007) What Causes Industry Agglomeration?. Evidence from Coagglomeration Patterns. HIER DP 2133, Harvard, Mass

Figueiredo O, Guimarães P, Woodward D (2002) Home-field advantage: location decisions of Portuguese entrepreneurs. J Urban Econ 52:341-361

Fleming M (2004) Techniques for estimating Spatially Dependent Discrete Choice Models. In: Anselin L, Florax R, Rey S (eds.) Advances in spatial econometrics, Springer, Amsterdam, pp $145-167$

Florax R, Folmer H (1992) Specification and estimation of spatial linear regression models: Monte Carlo evaluation of pre-test estimators. Reg Sci Urban Econ 22:405-432

Fujita M, Krugman P, Venables A (1999) The Spatial Economy. MIT press, Cambridge, Mass

Fujita M, Thisse J F (2002) Economics of agglomeration. Cities, industrial location and regional growth. Cambridge University Press, Cambridge

Gabe T, Bell K P (2004) Tradeoffs between Local Taxes and Government Spending as Determinants of Business Location, J Reg Sci 44 (1): 21-41

Glaeser E, Kallal H D, Scheinkman J A, Scheleifer A (1992) Growth in cities. J Polit Economy 100:1126-1152

Greene W H (2008) Econometric analysis. 6th edn. Prentice Hall, New York

Guimarães P, Rolfe R J, Woodward D (1998) Regional incentives and industrial location in Puerto Rico. Int Reg Sci Rev 21:119-138

Guimarães P, Figueiredo O, Woodward D (2003) A tractable approach to the firm location decision problem. Rev Econ Statist 85:201-204

Guimarães P, Figueiredo O, Woodward D (2004) Industrial location modelling: Extending the random utility framework. J Reg Sci 44:1-20

Haining R P (1995) Data problems in spatial econometric modelling. In: Anselin L, and Florax R J G M (eds) New Directions in Spatial Econometrics, Springer, Berlin, pp 156-171

Head K, Swenson D (1995) Agglomeration benefits and location choice: evidence from Japanese manufacturing investments in the United States. J Int Econ 38:223-247

Holl A (2004) Transport infrastructure, agglomeration economies, and firm birth. empirical evidence from Portugal. J Reg Sci 44:693-712

Hoover E M (1936) The measurement of industrial location. Rev Econ Statist 18:162-171

Jacobs J (1969) The Economy of Cities. Random House, New York

Kim, H.; Waddell, P.; Shankar, V.N. and Ulfarsson, G.F. (2008) Modeling micro-spatial employment location patterns: a comparison of count and choice approaches. Geog Anal 40: 123151 
Krugman P (1991) Geography and Trade. MIT Press, Cambridge, Mass.

McCann P, Sheppard S (2003) The rise, fall and rise again of industrial location theory. Reg Stud $37: 649-663$

Mc Fadden D (1974) Conditional Logit Analysis of Qualitative Choice Behaviour. In: Zarembka P (ed) Frontiers in Econometrics, Academic Press, New York, pp 105-142

Mc Fadden D (1978) Modelling the choice of residential location. In: Karlqvist A, Lundqvist L, Snickars F, Weibull J (eds) Spatial interaction theory and planning models, North Holland, Amsterdam, pp 75-96

Mc Fadden, D. (2001) Economic choices. Amer Econ Rev 91: 351-378

Marsh T, Mittelhammer R, Huffaker R (2000) Probit with spatial correlation by filed plot: Potato leafroll virus net necrosis in potatoes. J Agric Biol Environ Stat 5(1):22-38

Mohammadian A, Kanaroglou P S (2003) Applications of Spatial Multinomial Logit Model to Transportation Planning. Communication presented at the $10 \mathrm{t}^{\mathrm{h}}$ International Conference on Travel Behaviour Research. Lucerne, 10-15 of August.

Murdoch J, Sandler T, Vijverberg W P M (2003) The participation decision versus the level of participation in an environmental treaty: A spatial probit analysis. J Public Econ 87:337-362

Nelson G, De Pinto A, Harris V, Stone S (2004) Land use and road improvements: A spatial perspective. Int Reg Sci Rev 27(3):297-325

Rosenthal S S, Strange W C (2003) Geography, industrial organization and agglomeration. Rev Econ Statist 85:377-393

Strotmann, H (2007) Entrepreneurial survival. Small Bus Econ 28:87-104

Train K (2003) Discrete choice methods with simulation. Cambridge University Press, Cambridge. Vichiensan V, Tokunaga Y, Miyamoto K (2005) Mixed logit model framework with structuralized spatial effects: a test of applicability with area unit systems in location analysis. J East Asia Soc Transp Stud 6: 3789-3802

Viladecans E (2001) La concentración territorial de las empresas industriales: un estudio sobre el tamaño de las empresas y su proximidad geográfica. Pap Econ Española 89/90:308-319

Viladecans E (2004) Agglomeration economies and industrial location: City-level evidence. J Econ Geogr 4:565-580

Woodward D (1992) Locational determinants of Japanese manufacturing start-ups in the United States. Southern Econ J 58:690-708 


\section{Tables and figures}

Fig 1 Percentile Map on the distribution of industrial firms by municipality in the Region of Murcia (Spain)
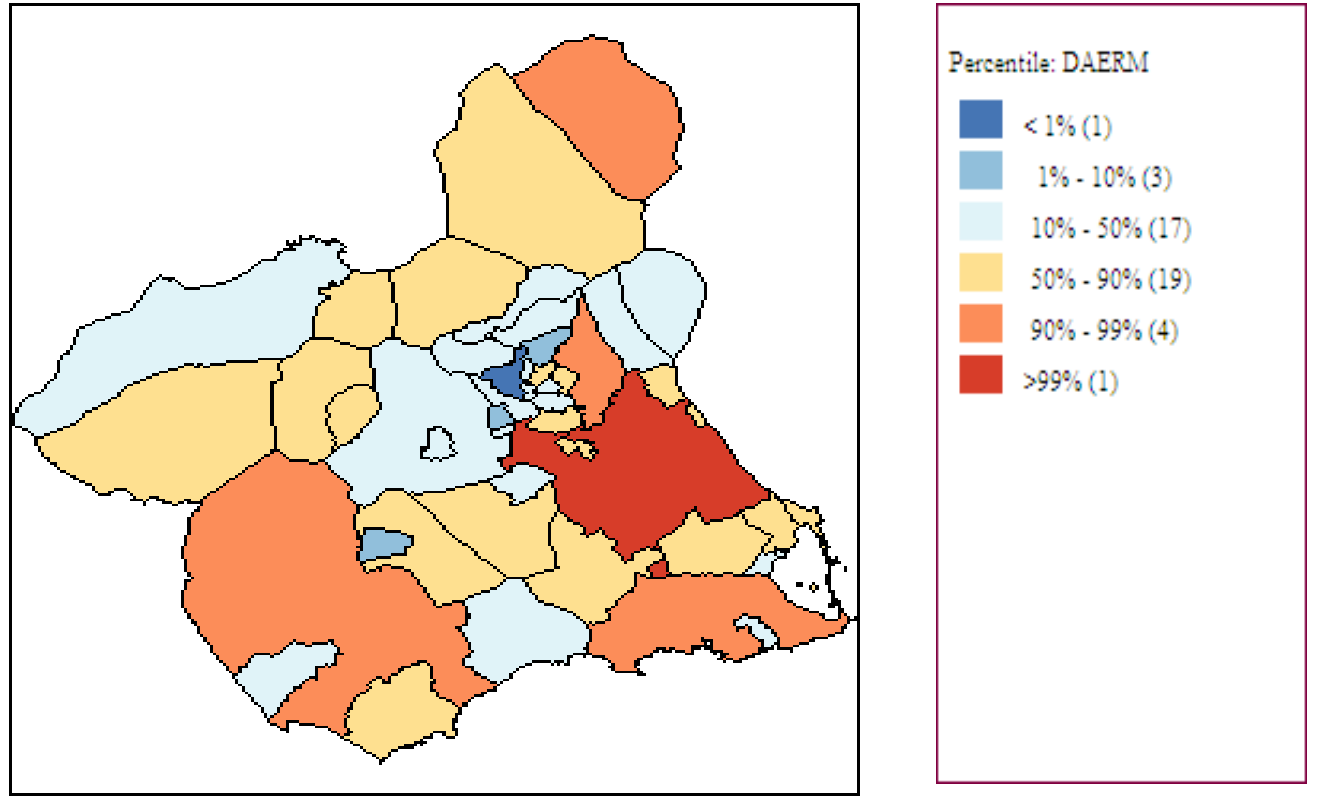

Table 1 Number of firms by sectors

\begin{tabular}{lcc}
\hline Sectors & $\begin{array}{c}\text { Number } \\
\text { of firms }\end{array}$ & $\begin{array}{c}\text { NACE Rev.1 } \\
\text { classif. (R93) }\end{array}$ \\
\hline FOOD, DRINKS AND TOBACCO & 1500 & $15+16$ \\
TEXTILES & 319 & $17(\mathrm{p})$ \\
CLOTHING & 350 & $17(\mathrm{p})$ \\
LEATHER AND SHOES & 290 & $18+19$ \\
WOOD AND CORK PRODUCTS & 552 & $20(\mathrm{p})+36$ \\
PRINTING, AND PUBLISHING & 515 & $21+22+23$ \\
CHEMICAL & 332 & 24 \\
RUBBER AND PLASTIC & 247 & 25 \\
NON METALLIC MINERALS & 637 & 14 \\
STEEL AND METAL PRODUCTS & 1458 & $13+27+28$ \\
AGRICULTURAL AND INDUSTRIAL & 611 & 29 \\
MACHINERY & & \\
OFFICE MACHINERY, ELECTRIC & 315 & $30+31+32+33$ \\
AND ELECTRONIC PRODUCTS & & $20(\mathrm{p})+26$ \\
FURNITURES AND OTHER & 1303 & \\
MANUFACTURES & $\mathbf{8 4 2 9}$ & \\
\hline TOTAL & & \\
\hline
\end{tabular}

Source: DAERM database. 
Table 2 Conditional Logit estimates (with and without space)

\begin{tabular}{|c|c|c|c|c|}
\hline \multirow[b]{2}{*}{ Variable } & \multicolumn{2}{|c|}{ Conditional Logit } & \multicolumn{2}{|c|}{$\begin{array}{c}\text { Spatial } \\
\text { Conditional Logit }\end{array}$} \\
\hline & coeff. & s.e. & coeff. & s.e. \\
\hline INDUSTRIAL SPECIALISATION & $0.2005^{* * *}$ & 0.0189 & $0.1537^{* * *}$ & 0.0167 \\
\hline DIVERSIFICATION & $0.7806^{* * *}$ & 0.0664 & $0.8920^{* * *}$ & 0.0711 \\
\hline HUMAN CAPITAL & $6.8039^{* * *}$ & 0.2783 & $5.6948^{* * *}$ & 0.2716 \\
\hline POPULATION & $0.0036^{* * *}$ & 0.0002 & $0.0038^{* * *}$ & 0.0002 \\
\hline INDUSTRY SHARE & $1.2593^{* * *}$ & 0.1424 & $0.6599^{* * *}$ & 0.0990 \\
\hline SERVICES SHARE & 0.2546 & 0.1717 & -0.0309 & 0.0773 \\
\hline INDUSTRIAL SURFACE & $0.8737^{* * *}$ & 0.0308 & $1.0377^{* * *}$ & 0.0272 \\
\hline$\delta$ & - & - & $0.8307^{* * *}$ & 0.0446 \\
\hline Log-likelihood & -25179.98 & & -25026.98 & \\
\hline Pseudo-R ${ }^{2}$ & 0.2106 & & 0.2154 & \\
\hline AIC & 0.1358 & & 0.1350 & \\
\hline $\operatorname{LR} \chi^{2}$ & $13433.92^{* * *}$ & & $13739.90^{* * *}$ & \\
\hline Number of obs. & 370876 & & 370876 & \\
\hline$\chi^{2}(\delta=1)$ & - & & 14.4236 & \\
\hline$(\delta=1) \mathrm{p}$-value & - & & 0.0001 & \\
\hline$(\delta \leq 1) \mathrm{p}$-value & - & & 0.9999 & \\
\hline$(\delta \geq 1) \mathrm{p}$-value & - & & 0.0001 & \\
\hline$R$ (in metres) & - & & 43650 & \\
\hline
\end{tabular}

$(* * *),(* *)$, and $(*)$ indicates significance at the $1 \%, 5 \%$ and $10 \%$ level.

Source: Own elaboration based on DAERM database.

Fig 2 Grid search for radius $R$ following the maximum-likelihood criterion

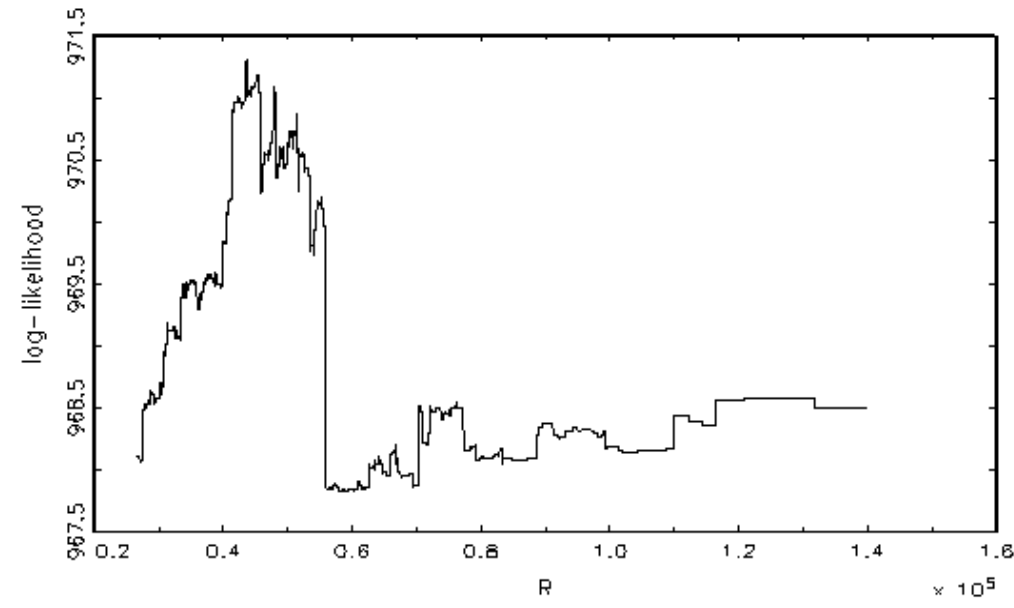


Table 3 Conditional Logit model: elasticities

\begin{tabular}{|c|c|c|c|c|c|c|c|c|}
\hline \multirow[b]{2}{*}{ Municipality $(j)$} & \multicolumn{7}{|c|}{ Explanatory variables $\left(X_{j}\right)$} & \multirow[b]{2}{*}{ Prob. } \\
\hline & $\begin{array}{l}\text { INDUSTR. } \\
\text { SPECIALIS. }\end{array}$ & DIVERS. & $\begin{array}{l}\text { HUMAN } \\
\text { CAPITAL }\end{array}$ & POPULAT. & $\begin{array}{c}\text { INDUSTR. } \\
\text { SHARE }\end{array}$ & $\begin{array}{l}\text { SERVICES } \\
\text { SHARE }\end{array}$ & $\begin{array}{l}\text { INDUSTR. } \\
\text { SURFACE }\end{array}$ & \\
\hline ABANILLA & 0.3368 & 0.6573 & 2.8063 & 0.0227 & 0.4295 & 0.1154 & 0.2054 & 0.0083 \\
\hline ABARAN & 0.1202 & 0.5598 & 3.3075 & 0.0465 & 0.0872 & 0.1759 & 0.0989 & 0.0069 \\
\hline AGUILAS & 0.0673 & 0.5176 & 3.6184 & 0.1168 & 0.0996 & 0.1319 & 0.2179 & 0.0102 \\
\hline ALBUDEITE & 0.0728 & 0.4560 & 2.7197 & 0.0051 & 0.4517 & 0.0609 & 0.0148 & 0.0037 \\
\hline ALCANTARILLA & 0.3351 & 0.6320 & 3.9319 & 0.1362 & 0.5309 & 0.0875 & 0.0136 & 0.0281 \\
\hline ALEDO & 0.1825 & 0.0000 & 3.0274 & 0.0036 & 0.6469 & 0.0981 & 0.0435 & 0.0046 \\
\hline ALGUAZAS & 0.4433 & 0.3173 & 3.2806 & 0.0295 & 0.5968 & 0.0936 & 0.0208 & 0.0103 \\
\hline ALHAMA & 0.6740 & 0.3360 & 3.3415 & 0.0672 & 0.2557 & 0.1705 & 0.2686 & 0.0148 \\
\hline ARCHENA & 0.2002 & 0.5203 & 3.7612 & 0.0598 & 0.4068 & 0.1175 & 0.0138 & 0.0143 \\
\hline BENIEL & 0.3610 & 0.5156 & 3.4333 & 0.0363 & 0.3622 & 0.1342 & 0.0086 & 0.0111 \\
\hline BLANCA & 0.1651 & 0.5529 & 3.1974 & 0.0220 & 0.3911 & 0.1022 & 0.0754 & 0.0077 \\
\hline BULLAS & 0.2548 & 0.2160 & 3.0548 & 0.0430 & 0.1635 & 0.0717 & 0.0714 & 0.0040 \\
\hline CALASPARRA & 0.3374 & 0.2989 & 2.7199 & 0.0361 & 0.5774 & 0.0603 & 0.1616 & 0.0056 \\
\hline CAMPOS DEL RIO & 0.8138 & 0.0773 & 3.1479 & 0.0075 & 0.9310 & 0.0272 & 0.0405 & 0.0137 \\
\hline CARAVACA & 0.3439 & 0.5502 & 3.6377 & 0.0874 & 0.6507 & 0.0813 & 0.7143 & 0.0483 \\
\hline CARTAGENA & 0.1076 & 0.1951 & 3.9902 & 0.7120 & 0.6516 & 0.0769 & 0.4584 & 0.0597 \\
\hline CEHEGIN & 0.3882 & 0.5485 & 3.3239 & 0.0556 & 0.6803 & 0.0753 & 0.2563 & 0.0188 \\
\hline CEUTI & 0.4905 & 0.4763 & 3.9409 & 315 & 0.5412 & 0.0629 & 0.0085 & 0.0244 \\
\hline CIEZA & 0.1388 & 0.6371 & 3.2752 & 0.1247 & 0.1871 & 0.1014 & 0.3173 & 0.0103 \\
\hline FORTUNA & 0.3565 & 0.6262 & 2.6482 & 0.0314 & 0.5843 & 0.0471 & 0.1293 & 0.0071 \\
\hline FUENTE ALAMO & 0.3428 & 0.5371 & 3.1798 & & & & 0.2366 & 0.0115 \\
\hline JUMILLA & 0.2791 & 0.6482 & 3.3654 & 0.0854 & 0.1976 & 0.1207 & 0.8283 & 0.0236 \\
\hline LA UNION & 0.1280 & 0.6066 & 3.4656 & 0.0579 & 0.2993 & 0.0948 & 0.0216 & 0.0092 \\
\hline LAS TORRES & 0.6178 & 0.4878 & 3.5339 & 0.0665 & 0.8148 & 0.0466 & 0.0332 & 0.0259 \\
\hline LIBRILLA & 0.2425 & 0.5400 & 2.5435 & 0.0152 & 0.5904 & 0.1014 & 0.0496 & 0.0050 \\
\hline LORCA & 0.1767 & 0.6364 & 3.2818 & 0.3086 & 0.2287 & 0.1205 & 1.3841 & 0.0542 \\
\hline LORQUI & 0.3396 & 0.6307 & 3.3279 & 0.0233 & 0.5285 & 0.1077 & 0.0138 & 0.0127 \\
\hline LOS ALCAZARES & 0.0752 & 0.5769 & 3.9380 & 0.0480 & 0.1358 & 0.1648 & 0.0173 & 0.0125 \\
\hline MAZARRON & 0.0527 & 0.5874 & 3.4644 & & 0.0585 & 0.1209 & 0.2762 & 0.0092 \\
\hline MOLINA & & 0.6432 & 4.0433 & & & 0.1107 & 0.1426 & 0.0403 \\
\hline MORATALLA & 0.4099 & 0.4428 & 2.8927 & 0.0298 & 0.8785 & 0.0266 & 0.8153 & 0.0228 \\
\hline MULA & 0.3115 & 0.3116 & 3.4656 & 0.0582 & 0.4594 & 0.0712 & 0.5447 & 0.0167 \\
\hline MURCIA & 0.0832 & 0.4731 & 3.2862 & 1.0432 & 0.1358 & 0.1204 & 0.5335 & 0.3108 \\
\hline PLIEGO & 0.1390 & 0.3461 & 2.6446 & 0.0134 & 0.0219 & 0.1447 & 0.0253 & 0.0023 \\
\hline PTO LUMBRERAS & 0.1059 & 0.6458 & 3.1490 & 0.0465 & 0.1335 & 0.1166 & 0.1259 & 0.0064 \\
\hline RICOTE & 0.1536 & 0.4355 & 2.9494 & 0.0054 & 0.1568 & 0.0127 & 0.0766 & 0.0037 \\
\hline SAN JAVIER & 0.0757 & 0.6167 & 4.1262 & 0.0985 & 0.0935 & 0.1517 & 0.0644 & 0.0168 \\
\hline SAN PEDRO & 0.1030 & 0.5333 & 3.4407 & 0.0764 & 0.1404 & 0.1609 & 0.0191 & 0.0075 \\
\hline SANTOMERA & 0.2255 & 0.6744 & 3.6588 & 0.0497 & 0.3077 & 0.1563 & 0.0379 & 0.0147 \\
\hline TORRE-PACHECO & 0.1260 & 0.6312 & 3.4728 & 0.1014 & 0.1193 & 0.1052 & 0.1635 & 0.0097 \\
\hline TOTANA & 0.2272 & 0.6054 & 3.0009 & 0.1022 & 0.3170 & 0.1071 & 0.2503 & 0.0086 \\
\hline ULEA & 0.3073 & 0.0000 & 3.4147 & 0.0036 & 0.0534 & 0.1456 & 0.0348 & 0.0044 \\
\hline VILLANUEVA & 0.0607 & 0.0000 & 3.7458 & 0.0069 & 0.0256 & 0.1190 & 0.0113 & 0.0044 \\
\hline YECLA & 0.6703 & 0.3181 & 3.6592 & 0.1166 & 0.8229 & 0.0601 & 0.4979 & 0.0550 \\
\hline
\end{tabular}

Elasticities are computed as: $\frac{\partial P_{j}}{\partial X_{m, j}} \frac{X_{m, j}}{P_{j}}=\left(1-P_{j}\right) \beta_{m} X_{m, j}$. 
Table 4 Spatial Conditional Logit model: elasticities

\begin{tabular}{|c|c|c|c|c|c|c|c|c|}
\hline \multirow[b]{2}{*}{ Municipality $(j)$} & \multicolumn{7}{|c|}{ Explanatory variables $\left(X_{j}\right)$} & \multirow[b]{2}{*}{ Prob. } \\
\hline & $\begin{array}{l}\text { INDUSTR. } \\
\text { SPECIALIS. }\end{array}$ & DIVERS. & $\begin{array}{l}\text { HUMAN } \\
\text { CAPITAL }\end{array}$ & POPULAT. & $\begin{array}{l}\text { INDUSTR. } \\
\text { SHARE }\end{array}$ & $\begin{array}{c}\text { SERVICES } \\
\text { SHARE } \\
\end{array}$ & $\begin{array}{l}\text { INDUSTR. } \\
\text { SURFACE }\end{array}$ & \\
\hline ABANILLA & 0.2579 & 0.7505 & 2.3465 & 0.0237 & 0.2250 & -0.0138 & 0.2437 & 0.0091 \\
\hline ABARAN & 0.0922 & 0.6400 & 2.7696 & 0.0487 & 0.0457 & -0.0210 & 0.1175 & 0.0063 \\
\hline AGUILAS & 0.0515 & 0.5902 & 3.0218 & 0.1219 & 0.0521 & -0.0157 & 0.2583 & 0.0123 \\
\hline ALBUDEITE & 0.0558 & 0.5211 & 2.2759 & 0.0053 & 0.2368 & -0.0073 & 0.0176 & 0.0037 \\
\hline ALCANTARILLA & 0.2575 & 0.7240 & 3.2992 & 0.1429 & 0.2791 & -0.0105 & 0.0162 & 0.0255 \\
\hline ALEDO & 0.1400 & 0.0000 & 2.5352 & 0.0038 & 0.3394 & -0.0117 & 0.0517 & 0.0039 \\
\hline ALGUAZAS & 0.3398 & 0.3628 & 2.7466 & 0.0308 & 0.3131 & -0.0112 & 0.0247 & 0.0099 \\
\hline ALHAMA & 0.5183 & 0.3853 & 2.8061 & 0.0706 & 0.1345 & -0.0205 & 0.3201 & 0.0114 \\
\hline ARCHENA & 0.1540 & 0.5969 & 3.1599 & 0.0628 & 0.2141 & -0.0141 & 0.0164 & 0.0104 \\
\hline BENIEL & 0.2765 & 0.5889 & 2.8716 & 0.0379 & 0.1898 & -0.0160 & 0.0103 & 0.0117 \\
\hline BLANCA & 0.1267 & 0.6328 & 2.6802 & 0.0230 & 0.2054 & -0.0122 & 0.0897 & 0.0061 \\
\hline BULLAS & 0.1952 & 0.2468 & 2.5561 & 0.0450 & 0.0857 & -0.0086 & 0.0847 & 0.0042 \\
\hline CALASPARRA & 0.2587 & 0.3417 & 2.2772 & 0.0378 & 0.3029 & -0.0072 & 0.1920 & 0.0051 \\
\hline CAMPOS DEL RIO & 0.6273 & 0.0889 & 2.6500 & 0.0079 & 0.4910 & -0.0033 & 0.0484 & 0.0079 \\
\hline CARAVACA & 0.2654 & 0.6330 & 3.0654 & 0.0921 & 0.3436 & -0.0098 & 0.8542 & 0.0417 \\
\hline CARTAGENA & 0.0827 & 0.2237 & 3.3505 & 0.7476 & 0.3428 & -0.0092 & 0.5463 & 0.0565 \\
\hline CEHEGIN & 0.2985 & 0.6290 & 2.7915 & 0.0584 & 0.3579 & 090 & 55 & 0.0154 \\
\hline CEUTI & 0.3784 & 0.5479 & 3.3200 & & 0.2856 & -0.0076 & 0.0102 & 0.0179 \\
\hline CIEZA & & & 2.7407 & & & 121 & & 0.0104 \\
\hline FORTUNA & 0.2731 & 0.7153 & 2.2151 & 0.0328 & 0.3062 & -0.0056 & 0.1534 & 0.0076 \\
\hline FUENTE ALAMO & 0.2622 & 0.6126 & 2.6562 & 0.0536 & 0.2420 & -0.0087 & 0.2805 & 0.0134 \\
\hline JUMILLA & 0.2139 & 0.7410 & 2.8175 & 0.0894 & 0.1036 & -0.0144 & 0.9841 & 0.0233 \\
\hline LA UNION & 0.0977 & 0.6901 & 2.8874 & 0.0603 & 0.1562 & -0.0113 & 0.0256 & 0.0136 \\
\hline LAS TORRES & 0.4763 & 0.5609 & 2.9759 & 0.0700 & 0.4298 & -0.0056 & 0.0397 & 0.0198 \\
\hline LIBRILLA & 0.1858 & 0.6171 & 2.1285 & 0.0159 & 0.3095 & -0.0121 & 0.0589 & 0.0050 \\
\hline LORCA & 0.1362 & 0.7317 & 2.7631 & 0.3250 & 0.1206 & -0.0145 & 1.6538 & 0.0485 \\
\hline LORQUI & 0.2604 & 0.7212 & 2.7870 & 0.0244 & 0.2773 & -0.0129 & 0.0164 & 0.0120 \\
\hline LOS ALCAZARES & 0.0574 & 0.6572 & 3.2855 & 0.0501 & 0.0710 & -0.0196 & 0.0204 & 0.0155 \\
\hline MAZARRON & & & 2.8897 & & & -0.0144 & 0.3269 & 0.0125 \\
\hline MOLINA & 0.2345 & 0.7406 & 3.4094 & 0.2109 & 0.2633 & -0.0133 & 0.1706 & 0.0330 \\
\hline MORATALLA & & 0.5052 & 2.4169 & & 0.4598 & -0.0032 & 0.9667 & 0.0245 \\
\hline MULA & 0.2397 & 0.3575 & 2.9119 & 0.0611 & 0.2418 & -0.0085 & 0.6495 & 0.0127 \\
\hline MURCIA & 0.0636 & 0.5392 & 2.7428 & 1.0888 & 0.0710 & -0.0144 & 0.6319 & 0.3127 \\
\hline PLIEGO & 0.1065 & 0.3953 & 2.2122 & 0.0140 & 0.0115 & -0.0173 & 0.0300 & 0.0028 \\
\hline PTO LUMBRERAS & 0.0807 & 0.7341 & 2.6215 & 0.0484 & 0.0696 & -0.0139 & 0.1487 & 0.0116 \\
\hline RICOTE & 0.1177 & 0.4976 & 2.4680 & 0.0057 & 0.0822 & -0.0015 & 0.0910 & 0.0038 \\
\hline SAN JAVIER & 0.0579 & 0.7031 & 3.4450 & 0.1028 & 0.0489 & -0.0181 & 0.0763 & 0.0191 \\
\hline SAN PEDRO & 0.0786 & 0.6073 & 2.8693 & 0.0797 & 0.0733 & -0.0192 & 0.0226 & 0.0110 \\
\hline SANTOMERA & 0.1728 & 0.7706 & 3.0616 & 0.0520 & 0.1613 & -0.0187 & 0.0450 & 0.0148 \\
\hline TORRE-PACHECO & 0.0960 & 0.7174 & 2.8906 & 0.1055 & 0.0622 & -0.0125 & 0.1932 & 0.0150 \\
\hline TOTANA & 0.1741 & 0.6915 & 2.5104 & 0.1069 & 0.1661 & -0.0128 & 0.2972 & 0.0090 \\
\hline ULEA & 0.2359 & 0.0000 & 2.8623 & 0.0038 & 0.0280 & -0.0174 & 0.0414 & 0.0028 \\
\hline VILLANUEVA & 0.0465 & 0.0000 & 3.1396 & 0.0072 & 0.0134 & -0.0142 & 0.0135 & 0.0029 \\
\hline YECLA & 0.4981 & 0.3525 & 2.9695 & 0.1184 & 0.4184 & -0.0070 & 0.5734 & 0.0836 \\
\hline
\end{tabular}

Elasticities are computed as: $\frac{\partial P_{j}}{\partial X_{m, j}} \frac{X_{m, j}}{P_{j}}=\left(1-P_{j}\right) \beta_{m} X_{m, j}$. 


\section{Appendix}

Table A.1 Definition of the explanatory variables

\begin{tabular}{|c|c|c|}
\hline Variable & Definition & Source \\
\hline $\begin{array}{l}\text { INDUSTRIAL } \\
\text { SPECIALISATION }\end{array}$ & $\begin{array}{l}\text { Industrial specialisation index computed as } \\
\qquad \frac{E_{j}^{s} / \sum_{s^{\prime}=1}^{S} E_{j}^{s^{\prime}}}{\sum_{j^{\prime}=1}^{J} E_{j^{\prime}}^{s} / \sum_{s^{\prime}=1}^{S} \sum_{j^{\prime}=1}^{J} E_{j^{\prime}}^{s^{\prime}}} \\
\text { where } E_{j}^{s} \text { denotes sector } s \text { employment in the } \\
\text { municipality } j\end{array}$ & $\begin{array}{l}\text { DAERM database } \\
\text { (Regional } \\
\text { Statistical Office } \\
\text { of Murcia). }\end{array}$ \\
\hline DIVERSIFICATION & $\begin{array}{l}\text { Diversification index computed as } \\
\qquad 1-\sum_{r \in I}\left(E_{j}^{r} / \sum_{r^{\prime} \in I} E_{j}^{r^{\prime}}\right)^{2} \\
\text { where } E_{j}^{r} \text { denotes industrial employment in sector } r \\
\text { and municipality } j \text { over total industrial employment } \\
\text { in the municipality } j \text {. The index takes values in the } \\
\text { interval }(0,1) \text {, where } 0 \text { indicates the lowest degree of } \\
\text { diversification while } 1 \text { is associated to the highest } \\
\text { degree of diversification }\end{array}$ & $\begin{array}{l}\text { DAERM database } \\
\text { (Regional } \\
\text { Statistical Office } \\
\text { of Murcia). }\end{array}$ \\
\hline HUMAN CAPITAL & $\begin{array}{l}\text { Percentage of labour force with secondary and } \\
\text { tertiary levels of education by municipality }\end{array}$ & $\begin{array}{l}\text { Population Census, } \\
\text { Spanish National } \\
\text { Statistics Institute } \\
\text { (INE) }\end{array}$ \\
\hline POPULATION & Total population by municipality & $\begin{array}{l}\text { Population Census, } \\
\text { Spanish National } \\
\text { Statistics Institute } \\
\text { (INE) }\end{array}$ \\
\hline INDUSTRY SHARE & $\begin{array}{l}\text { Share of local industrial employment over regional } \\
\text { industrial employment }\end{array}$ & $\begin{array}{l}\text { DAERM database } \\
\text { (Regional } \\
\text { Statistical Office } \\
\text { of Murcia) }\end{array}$ \\
\hline SERVICES SHARE & $\begin{array}{l}\text { Share of local services employment over regional } \\
\text { services employment }\end{array}$ & $\begin{array}{l}\text { Regional Accounts } \\
\text { (CRE), Spanish } \\
\text { National Statistics } \\
\text { Institute (INE) }\end{array}$ \\
\hline $\begin{array}{l}\text { INDUSTRIAL } \\
\text { SURFACE }\end{array}$ & Industrial land availability by municipality & $\begin{array}{l}\text { sueloindustrial- } \\
\text { murcia.com/index. } \\
\mathrm{htm}\end{array}$ \\
\hline
\end{tabular}

